60th anniversary of Thorax

\section{Thorax in the early 1970s}

\section{Ogilvie}

W hen I edited Thorax in the early 1970s, it was the official publication of the old Thoracic Society whose membership included surgeons. There was therefore a surgical as well as a medical editor. This was the dawning era of open heart surgery, so many of the surgical papers dealt with this topic but also (since Thorax was an anatomical concept) with oesophageal disorders.

A change in the growing points of respiratory medicine is revealed by a comparison of papers published in the
June 2006 issue of Thorax with those published when I was editor. About one third of all medical papers appearing in 1973 dealt with advances in lung physiology compared with only one of 21 articles in the June issue. Conversely, some current topics were scarcely heard of in the early 1970s: sleep apnoea, CT scans, and many advances in the genetics and biochemistry of the lung.

Thorax now reflects the highest standards of current respiratory research. The editorial team should be proud to attract such distinguished contributions.

Editor, 1971-1977

Thorax 2006;61:1017.

doi: 10.1136/thx.2006.072322

60th anniversary of Thorax

\title{
The old case: Thorax in the 1970s
}

\section{A Seaton}

A $\mathrm{s}$ a young consultant in Cardiff in the 1970s I inherited two things: a battered old brown bakelite case that had been carried by earlier South Wales tuberculosis doctors and the editorship of Thorax. The two fitted well together. The work was shared with the surgical editors, Ben Milstein then Hugoe Matthews, who dealt with thoracic surgery and anatomy, the rest coming to me. The BMJ agreed to buy me an electric typewriter and pay secretarial expenses. Approximately one or two papers arrived each day, to be filed in the brown case. This held about 15 , and it was possible to carry a week's work together with my stethoscope wherever I went; when it was full I knew I had to deal with it. The process was quite simple and conducted by letter. Like my predecessors, I read every paper, decided whether it was of sufficient interest and, if it was, wrote to a referee asking for his or her opinion on the science and giving my personal views, thus immediately introducing a bias. Sometimes, if I didn't think it at all interesting, I rejected it politely but firmly without asking a referee. Occasionally this attracted some discussion with the authors and once resulted in a death threat (from an overseas colleague), but generally caused no problems other than having to be wary of meeting disappointed colleagues at conferences.
The process of refereeing was interesting. I also had a wide range of very helpful colleagues and most were very fair referees. Occasionally, however, some were undoubtedly destructive and motivated by rivalry or a personal dislike of the authors or their ideas. Sometimes they found no scientific fault but blamed the authors for not doing a completely different study. I occasionally used two referees when I had questions about the first one, and I sometimes published papers that referees didn't like. It was often possible to predict a referee's response, and this allowed me to steer papers to sympathetic ones when I thought the work interesting. It also allowed me to learn the characteristic refereeing styles of many colleagues, so for years I was able to guess the names of referees of my own papers.

What are referees for? To guide an editor as to whether the science is valid, the analysis appropriate, and the work original - not to usurp the editorial role of deciding what is most likely to interest the journal's readers. Although the journal had already been well established as an international one by my predecessors, I had a strong sense that it was the Thoracic Society's journal and, since I knew almost all the members, I had a fair view as to what would be of interest to them. Two refereeing moments stick in my memory. One rather obscure physiological paper seemed good to me, and Neil Pride as referee agreed, with one small proviso-he recalled reading exactly the same paper from the same author 15 years before! Editors bewarepeople now rarely look back more than five. Another rather indifferent paper reached me on the same day that it also came to me for refereeing from the $B M J$ bad luck on the authors, as both were rejected and they got a stern letter from Stephen Lock.

In those days a journal's circulation depended on library subscriptions primarily and this was affected more by the price of the dollar than by the journal's content. Our motivation was to produce a journal that our readers would enjoy and find educational, but we were not troubled by citation indices. European doctors sent their best work to European journals, which were generally more readable than American ones; in my opinion they still should. Because American journals are sent to more people and thus quoted by more does not make the reported work any better and, in these www days, does not influence greatly the chances of a good paper being read by those who are interested. Progress of science does not depend on research assessment exercises and citation indices but on good ideas, carefully tested and clearly explained in journals like Thorax.

Several things of note happened during my tenure. Ben Milstein changed the colour of the cover from bilious postwar yellow to shiny silver-the nicest it has ever been in my biased opinion. We decided to publish editorials and I wrote the first one myself for the first issue of 1978: "Asthma - contrasts in care". It is interesting to re-read it almost 30 years later, as it took some 25 years for my suggestions to be taken up. We also introduced 600 word short reports and a fascinating series on the Thorax in 